\title{
Review
}

\section{Dietary Influences on the Microbiota-Gut-Brain Axis}

\author{
Thomas M. Barber ${ }^{1,2}$, Georgios Valsamakis ${ }^{1,3}$, George Mastorakos ${ }^{3}$, Petra Hanson 1,2 $\mathbb{D}$, Ioannis Kyrou 1,2,4, \\ Harpal S. Randeva ${ }^{1,2,4}$ and Martin O. Weickert $1,2,5, *$ (D)
}

1 Warwickshire Institute for the Study of Diabetes, Endocrinology and Metabolism, University Hospitals Coventry and Warwickshire NHS Trust, Clifford Bridge Road, Coventry CV2 2DX, UK; t.barber@warwick.ac.uk (T.M.B.); gedvalsamakis@yahoo.com (G.V.); drpetrahanson@gmail.com (P.H.); kyrouj@gmail.com (I.K.); harpal.randeva@uhcw.nhs.uk (H.S.R.)

2 Division of Biomedical Sciences, Warwick Medical School, University of Warwick, Coventry CV2 2DX, UK

3 Endocrine Unit, 2nd Department of Obstetrics and Gynaecology and Pathology Department, Aretaieion University Hospital, Athens Medical School, 11528 Athens, Greece; mastorakg@ath.forthnet.gr

4 Aston Medical Research Institute, Aston Medical School, College of Health and Life Sciences, Aston University, Birmingham B4 7ET, UK

5 Centre for Sport, Exercise and Life Sciences, Faculty of Health \& Life Sciences, Coventry University, Coventry CV1 5FB, UK

* Correspondence: Martin.Weickert@uhcw.nhs.uk

check for updates

Citation: Barber, T.M.; Valsamakis,

G.; Mastorakos, G.; Hanson, P.; Kyrou,

I.; Randeva, H.S.; Weickert, M.O.

Dietary Influences on the

Microbiota-Gut-Brain Axis. Int. J.

Mol. Sci. 2021, 22, 3502. https://

doi.org/10.3390/ijms22073502

Academic Editor: Silvia Melgar

Received: 21 February 2021

Accepted: 24 March 2021

Published: 28 March 2021

Publisher's Note: MDPI stays neutral with regard to jurisdictional claims in published maps and institutional affiliations.

Copyright: (c) 2021 by the authors. Licensee MDPI, Basel, Switzerland. This article is an open access article distributed under the terms and conditions of the Creative Commons Attribution (CC BY) license (https:/ / creativecommons.org/licenses/by/ $4.0 /)$.
Abstract: Over unimaginable expanses of evolutionary time, our gut microbiota have co-evolved with us, creating a symbiotic relationship in which each is utterly dependent upon the other. Far from confined to the recesses of the alimentary tract, our gut microbiota engage in complex and bi-directional communication with their host, which have far-reaching implications for overall health, wellbeing and normal physiological functioning. Amongst such communication streams, the microbiota-gut-brain axis predominates. Numerous complex mechanisms involve direct effects of the microbiota, or indirect effects through the release and absorption of the metabolic by-products of the gut microbiota. Proposed mechanisms implicate mitochondrial function, the hypothalamus-pituitary-adrenal axis, and autonomic, neuro-humeral, entero-endocrine and immunomodulatory pathways. Furthermore, dietary composition influences the relative abundance of gut microbiota species. Recent human-based data reveal that dietary effects on the gut microbiota can occur rapidly, and that our gut microbiota reflect our diet at any given time, although much inter-individual variation pertains. Although most studies on the effects of dietary macronutrients on the gut microbiota report on associations with relative changes in the abundance of particular species of bacteria, in broad terms, our modern-day animal-based Westernized diets are relatively high in fats and proteins and impoverished in fibres. This creates a perfect storm within the gut in which dysbiosis promotes localized inflammation, enhanced gut wall permeability, increased production of lipopolysaccharides, chronic endotoxemia and a resultant low-grade systemic inflammatory milieu, a harbinger of metabolic dysfunction and many modern-day chronic illnesses. Research should further focus on the colony effects of the gut microbiota on health and wellbeing, and dysbiotic effects on pathogenic pathways. Finally, we should revise our view of the gut microbiota from that of a seething mass of microbes to one of organ-status, on which our health and wellbeing utterly depends. Future guidelines on lifestyle strategies for wellbeing should integrate advice on the optimal establishment and maintenance of a healthy gut microbiota through dietary and other means. Although we are what we eat, perhaps more importantly, we are what our gut microbiota thrive on and they thrive on what we eat.

Keywords: gut microbiota; brain; diet; appetite; metabolism

\section{Introduction}

Hippocrates, the father of modern medicine, said that all disease originates within the gut. It has taken millennia for the prescience of the great man to truly manifest. Over 
the last two decades, there has been a transformation in our understanding of the role of the gut and its resident microbiota in health and disease. Far from being simply a system whereby digestion and the absorption of nutrients and water occurs, the gastrointestinal system plays an essential role in the maintenance of health and wellbeing, and a central pathogenic role in the origin of much of the 21st century chronic illness burden. These include atopies, food intolerances, auto-immunities, and chronic inflammatory, cardiometabolic and neuro-psychiatric conditions [1]. The gut microbiota provides a zeitgeist for the host and plays a central role as a determinant of health or disease; as such, it behaves like an organ in its own right, integral to both the gastrointestinal system and normal physiological function.

The term 'microbiota' is an umbrella that incorporates the many prokaryotes (bacteria), eukaryotic microorganisms (such as fungi and protozoans), archaea and viruses that associate with the human body, including the skin, genitourinary tract, respiratory epithelia and the gastrointestinal tract. The human microbiota has been estimated to consist of $>30$ trillion microbes, a similar order of magnitude to the number of our own cells [2]. The majority of the human microbiota reside within the gut, and whilst occupying the entire gastrointestinal tract, the majority (around 70\%) of these microbes exist within the colon [3]. Our gut microbiota co-evolved with us over hundreds of millions of years. Over this unimaginable expanse of evolutionary time, our immune systems developed integrally and intricately in a myriad of ways with our gut microbiota. This inter-dependence between our gut microbiota and our immune system forms a key component of our understanding of the importance of the gut microbiota for the maintenance of health and avoidance of disease. Our immune system depends on our gut microbiota for its normal development, whilst our gut microbiota depend on the tolerability of our immune system for its survival: a truly symbiotic relationship. Indeed, arguably the gut microbiota and immune system are not separate entities, but rather a truly interlinked system, with one depending upon the other [4].

Our understanding of the gut microbiota remains very much in its infancy. There are four major microbial phyla that comprise $>90 \%$ of the bacteria within the gut microbiota: Bacteroides, Firmicutes, Actinobacteria and Proteobacteria [5]. In addition to bacteria, our gut microbiota also consists of viruses, fungi, Amoebozoa and archaea [6]. Certain strains of microbes associate with favourable health, such as Firmicutes and Cytophaga, Flavobacterium and Bacteroides [5], and others associate with chronic illness (e.g., obesity and metabolic dysfunction) [7-12]. However, these association data on which much of the current literature is based do not provide insight into causation or pathogenesis of disease. Furthermore, there are clear limitations from focusing on one strain of microbe in isolation from the myriad and countless other microbes within its vicinity, all of which interact with each other and with the host. Based on current data, our notion of a healthy gut microbiota (except for the neonatal period) is one that manifests a rich and diverse array of microbes. Such a scenario appears essential for the normal and healthy development of the immune system. Intriguingly, currently only around 1000 species of human microbiota have been identified [3], suggesting that perhaps the vast majority of the gut microbiota remain unknown to us. Furthermore, we have limited or no knowledge or understanding of the impact on human health of many of the known gut microbiota [13].

In this concise review, we focus on the microbiota-gut-brain axis and explore the complex mechanisms that bi-directionally link the gut microbiota with the brain. We also outline current evidence to support the influence of dietary macronutrients on the gut microbiota.

\section{The Microbiota-Gut-Brain Axis}

Traditionally, we considered the gastrointestinal and central nervous systems as separate entities. Accordingly, we also considered gastrointestinal and neuro-psychiatric disorders as separate from one another, with respective etiopathogeneses in silos. Furthermore, until relatively recently, we thought the main role of the colon was for water 
absorption. Although we had awareness of the gut as a seething mass of microbes, we understood these microbes as such: a seething mass with little known physiological function or importance, other than being a potential source of life-threatening infection following breach of the wall of the gastrointestinal canal.

Our modern understanding of the gut microbiota places it as a central determinant for health and wellbeing, with much of the modern-day 21st century chronic illness burden linked to dysbiosis within the gut microbiota [14]. Indeed, the gut microbiota is implicated in the pathogenesis of many neuro-psychiatric disorders, including Parkinson's disease [15], autism spectrum disorder [16], chronic pain [17] and disorders of mood and affect [18]. Based on such compelling data, it is timely to modify our traditional view of the gut and the brain as separate entities and replace this with a model in which there is intricate linkage of the gut and its microbiota with the brain through multiple complex and bidirectional pathways: a microbiota-gut-brain axis. From this modern perspective, health and wellbeing depend upon normal functioning of both the gut microbiota and the brain. Furthermore, any pathology that affects either the gut microbiota or the brain does not occur in isolation, but rather impacts on both systems.

Much of our modern insight into the microbiota-gut-brain axis stems from metabolomics data from rodent-based studies [19]. For example, rodent-based models reveal an association between the gut microbiota and levels of important neurotransmitters within the brain. Germ-free (GF) rodents manifest a reduction in the expression of brain-derived neurotrophic factor (BDNF), primarily within the hippocampus [20]. Conversely, rodent models with healthy gut microbiota show increased expression of BDNF within the brain [21]. Furthermore, the gut microbiota also associate with the levels of neuroreceptors within the brain. The gamma-amino butyric acid (GABA) receptor mediates the effects of the eponymous major inhibitory neurotransmitter in the brain and regulates numerous psychological and physiological processes [1,19], including the pathogenesis of anxiety and depression [19]. In one rodent-based study, compared with control-fed mice, chronic ingestion of Lactobacillus rhamnosus (JB-1) resulted in regionally dependent changes in GABA receptor expression within the brain, with increases in GABA receptor expression in cortical regions and reductions in the prefrontal cortex and amygdala [19]. These changes in central GABA receptor expression are associated with reduced anxiety- and depression-related behaviour [19]. Other rodent studies showed an association between the gut microbiota and the expression of other neuroreceptors, such as the N-methyl-D-aspartate (NMDA) receptor (which mediates the effects of the excitatory neurotransmitter glutamate) [21], and the central expression of serotonin receptor 1A [19] and tryptophan [22]. Furthermore, gut microbiota-induced changes in the expression of neuroreceptors often associate with altered emotional behaviours [19,21]. As outlined, compelling evidence links the gut microbiota with brain neurotransmission and neuroreceptors, including emotions and behaviour. Thus, it is important to explore the underlying mechanisms and complex pathways that mediate these effects and provide a foundation for the microbiota-gut-brain axis.

\section{Mechanisms That Link the Gut Microbiota with the Brain}

The complex bi-directional pathways that link the gut microbiota with the brain implicate mitochondrial function, the hypothalamus-pituitary-adrenal axis, and autonomic, neuro-humeral, entero-endocrine and immuno-modulatory pathways. Furthermore, direct links between the gut microbiota and the brain may occur through the release and absorption of the metabolic by-products of the microbiota within the gut [23]. In this section, we outline the current evidence to support the major proposed pathways that link the gut microbiota with the brain (summarized in Figure 1).

\subsection{Metabolic By-Products of the Gut Microbiota and Incretin Hormones}

The gut microbiota utilize energy from food products ingested by the host, and in the process release by-products of their metabolism that include short chain fatty acids (SCFAs), secondary bile acids and tryptophan metabolites [19,24]. These metabolic by- 
products of the gut microbiota likely mediate at least some of the pathways that link the gut microbiota with the brain, either directly or indirectly, through the modulation of signals from enterochromaffin and entero-endocrine cells and the regulation of the mucosal immune system and inflammatory pathways. Interestingly, SCFAs and secondary bile acids also influence host energy production, with implications for athletic performance [25].

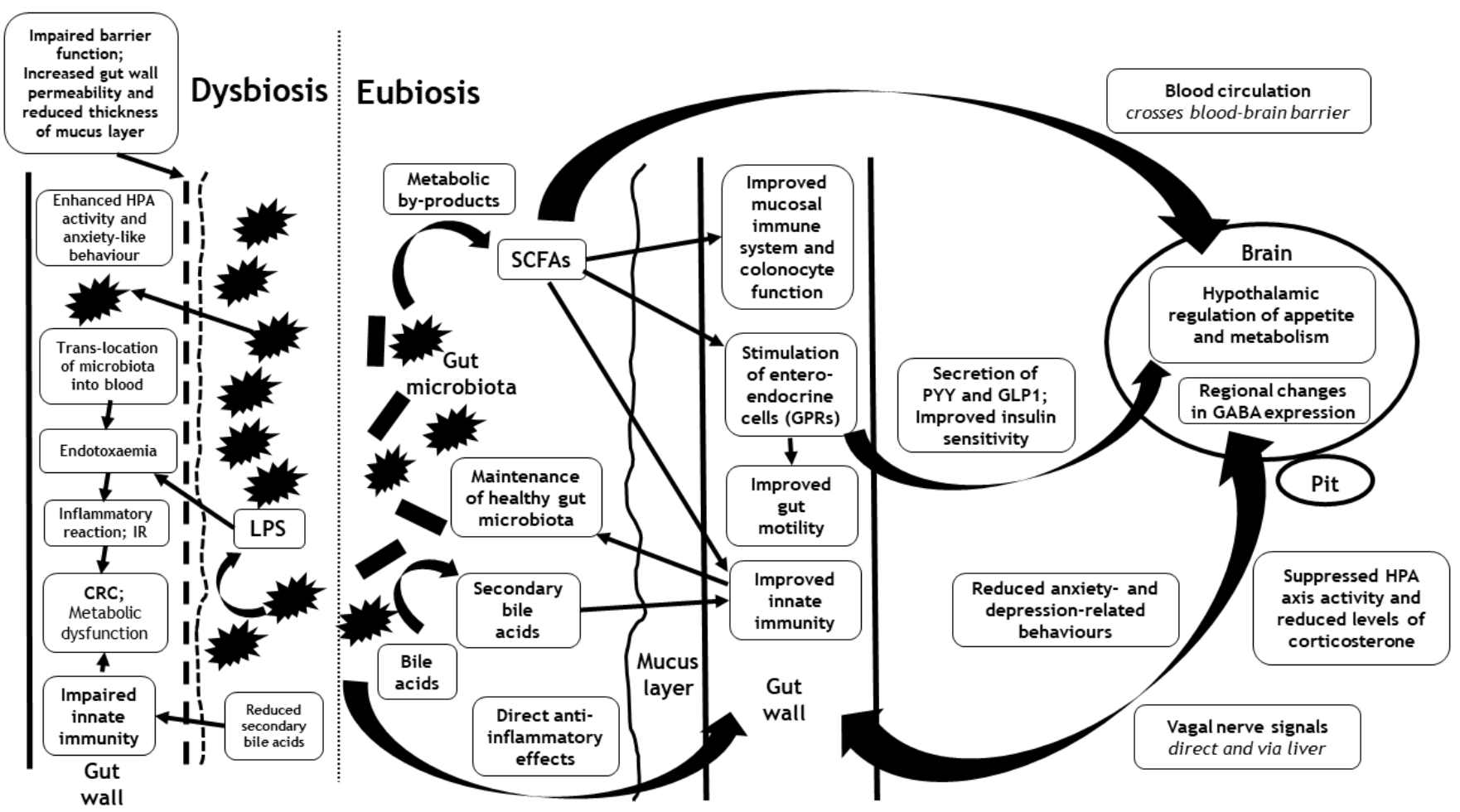

Figure 1. Outline of the major proposed pathways that link the gut microbiota with the brain during eubiosis and dysbiosis, including the hypothalamus-pituitary-adrenal axis (HPA) and autonomic, neuro-humeral, entero-endocrine and immunomodulatory pathways. Interactions may occur directly through translocation of the gut microbiota or their cell walls (endotoxaemia) and/or through the release and absorption of the metabolic by-products of the gut microbiota (such as short chain fatty acids (SCFAs)). Although the interactions between the gut microbiota (and their metabolic by-products) and the brain are mediated via similar pathways in eubiosis and dysbiosis, their effects are opposed. Eubiosis associates with the suppression of the HPA axis and the alleviation of anxiety, whereas dysbiosis associates with enhancement of the HPA axis and anxiety-like behaviour. CRC = colorectal cancer; GABA = gamma-amino butyric acid; GLP1 = glucagonlike peptide-1; GPRs = G protein-coupled receptors; HPA = Hypothalamus-pituitary adrenal; IR = Insulin resistance; LPS = lipopolysaccharide; Pit = pituitary; PYY = peptide YY; SCFA = Short chain fatty acid.

Amongst the metabolic by-products of the gut microbiota, there has been much focus on SCFAs, produced by caecal anaerobic microbes, such as Enterococcus (a Grampositive facultative anaerobe of the genus Lactobacillus and phylum Firmicutes), during the fermentation of dietary fibre (non-digestible carbohydrates). SCFAs (and levels of colonic Enterococcus) appear to associate with some beneficial effects to the host, including the inhibition of appetite [26]. Furthermore, SCFAs may cross the intestinal barrier into the systemic circulation, and the blood-brain barrier into the brain parenchyma to exert direct effects on the hypothalamic regulation of metabolism and appetite [27,28]. In addition to direct hypothalamic effects, SCFAs may influence the regulation of metabolism and appetite indirectly through entero-endocrine effects, and glucose, lipid and cholesterol metabolism through effects on G protein-coupled receptors (GPRs) [29]. Expressed within gut adipocytes, immune cells and entero-endocrine cells, there are two SCFA-specific GPRs: GPR41 / free fatty acid receptor 3 (FFAR3) and GPR43/FFAR2 [30]. In a rodent-based study, SCFA stimulation of GPR41 on entero-endocrine cells resulted in enhanced secretion of 
peptide YY (PYY, a potent appetite-suppressant gut-derived incretin hormone), increased gut motility and reduced harvesting of energy via SCFAs from the diet in wild-type mice vs. GPR41 knockout mice [31]. GPR43 may also mediate SCFA-dependent effects on the optimized release of incretin hormones, such as glucagon-like peptide-1 (GLP-1) and enhanced insulin sensitivity [32]. Finally, SCFAs may provide a useful source of energy for colonocyte function [33].

Some human-based studies also suggest beneficial metabolic effects of SCFAs. One study explored the metabolic effects of the ingestion of a novel inulin-propionate ester (propionate, a common SCFA produced by the human gut microbiota) compared with an inulin control group in overweight adults $(n=60)$ using a randomized, controlled, crossover design [34]. The ingestion of propionate resulted in an early postprandial release of the incretin hormones, PYY and GLP-1 from human colonic cells, and reduced caloric intake. Furthermore, over 24 weeks of regular propionate ingestion, there was significant weight loss, reduced hepatic lipid content and intra-abdominal adipose tissue volume and preserved insulin sensitivity [34]. These data support an important role for SCFAs in the mediation of the metabolic and appetitive effects of the gut microbiota through entero-endocrine pathways.

Despite some support for the favourable metabolic effects of SCFAs, there remains controversy within the literature regarding the magnitude and nature of such benefits. As metabolic by-products of the gut microbiota, SCFA production depends upon fermentation, a process optimized by the ingestion of the soluble form of dietary fibre. However, our group has demonstrated that the ingestion of insoluble cereal fibres from wheat or oat extracts and whole grain products (demonstrated as non-fermentable in vivo and in vitro [35]), and not the soluble and highly fermentable types of dietary fibre, associates with improved insulin sensitivity and risk for the development of type 2 diabetes mellitus (T2D) [36] This is an important observation, which appears to contradict an important role of SCFAs (produced during fermentation) in the mediation of the insulin sensitizing effects of the gut microbiota, as outlined above. A further study from our group compared the metabolic effects of isoenergetic high-protein versus high-cereal fibre diets, randomly assigned to overweight adults with features of metabolic syndrome [37]. After six weeks of each diet, insulin sensitivity significantly improved in those participants assigned to the high-cereal fibre diet compared with those assigned to the high-protein diet [37]. Cereal fibre is insoluble and has a limited capacity for fermentation by the gut microbiota, and therefore limits any attendant production of metabolic by-products, such as SCFAs, from the gut microbiota. Therefore, these data corroborate the view that the improved insulin sensitivity resulting from the ingestion of insoluble cereal fibre, cannot be explained solely through fermentation by the gut microbiota and resultant SCFA production, and alternate explanations are required [37]. Furthermore, although the intake of dietary fibre can influence serum levels of PYY [38], this does not necessarily translate into improved satiety or metabolic benefits [39]. Despite these caveats and controversies, SCFAs probably contribute up to $10 \%$ of the energy we extract from our food [40-43]. Future studies should explore the effects of SCFAs on other incretin hormones known to affect appetite regulation, such as glucose-dependent insulinotropic polypeptide (GIP) [44-46].

The gut microbiota also bio-convert bile acids (synthesized from cholesterol within the liver) into secondary bile acids. This bioconversion is important, as secondary bile acids contribute towards innate immunity, insulin sensitivity and optimal regulation of host metabolic pathways (including carbohydrate and lipid metabolism) through the modulation of signalling pathways via the G protein-coupled membrane receptor 5 (TGR5) and the nuclear farnesoid X receptor (FXR) [47]. Furthermore, secondary bile acids, through modulation of the intestinal innate immune response, also ensure the maintenance of a healthy gut microbiota [47-49]. Dysbiosis within the gut microbiota associates with the aberrant bioconversion of bile acids into secondary bile acids, which in turn results in both metabolic dysfunction and gastrointestinal carcinogenesis (including colorectal cancer and hepatocellular carcinoma) [48]. 
Succinate is another metabolic by-product of the gut microbiota and is produced by colonic bacterial species such as Prevotellaceae and Veillonellaceae [14]. Similar to SCFAs, succinate also crosses the intestinal wall and appears within the circulation. However, succinate associates unfavourably with health. Indeed, serum succinate levels associate with obesity and metabolic syndrome, and conversely weight loss associates with a reduction in serum levels of succinate and an increase in the proportion of succinate-consuming colonic bacteria, including Odoribacteraceae and Clostridiaceae [50]. Unlike SCFAs however, any potential role for succinate in mediating links between the gut microbiota and the brain remains unidentified. Succinate may simply represent an inert serum biomarker of succinate-producing colonic microbiota, without any causative role in the pathogenesis of disease. Future research should explore a possible role for succinate in the mediation of the microbiota-gut-brain axis.

\subsection{Mitochondrial Function}

There are complex bi-directional interlinks between the gut microbiota and host mitochondrial function [14] which are influenced by genetic variants within the mitochondrial genome [25]. The gut microbiota regulate key enzymes, transcription factors and transcriptional co-activators involved in mitochondrial biogenesis in the host. Mitochondrial function (including the mitochondrial production of reactive oxygen species) influences the host response to the gut microbiota (including mucosal immune responses and intestinal barrier function), and in turn helps to regulate the gut microbiota [14]. The development of autism spectrum disorder possibly implicates mediating effects of mitochondrial function induced by colonic butyrate [14]. Neuronal mitochondrial dysfunction (affecting neuronal function and neuron cell numbers) may mediate the effects of gut dysbiosis on depression [51]. Possible pathways include SCFAs, brain inflammatory processes following gut permeability and increased blood lipopolysaccharide (LPS) levels [51].

\subsection{Hypothalamus-Pituitary-Adrenal (HPA) Axis}

Rodent-based studies suggest a link between the gut microbiota and activity within the HPA axis. Germ-free (GF) mice manifest enhanced basal or stimulated HPA axis activity [19], whereas in normal mice, probiotics induced suppression of HPA axis activity (reflected by reduced levels of corticosterone) [19]. It has been hypothesized that increased HPA axis activity in GF mice may reflect a loss of microbiota-related energy sources [1]. Interestingly, although some controversy exists regarding the concordance of anxiety-like behaviours and the activity of the HPA axis, in one study, GF mice did manifest both increased HPA axis responsiveness and anxiety-like behaviour [52]. The gut microbiota influence the activity of the HPA axis through several mediators that cross the blood-brain barrier. These include cytokines, prostaglandins and microbial antigens [53]. Furthermore, activation of the HPA axis may influence the gut microbiota and intestinal permeability [53]. Severe mental disorders such as bipolar disorder, schizophrenia and depression associate with dysbiosis, intestinal permeability and dysregulation of the HPA axis [53]. Although complex bi-directional pathways exist, dysbiosis may predispose individuals to mental disorders through multiple mechanisms that include HPA axis dysregulation [53].

\subsection{Autonomic Signals}

Compelling rodent-based data promote an important role for the autonomic nervous system in the mediation of signalling between the gut microbiota and the brain. In one study by Bravo and colleagues, chronic ingestion of a Lactobacillus strain associated with regional changes in GABA expression within the brain, reduced stress-induced HPA axis activity and anxiety- and depression-related behaviours. However, these effects did not occur in vagotomised mice [19]. Therefore, the vagus nerve appears to play a central role in mediating bi-directional signals between the gut microbiota and the brain. Some of the autonomic signalling between the gut microbiota and the brain likely implicate the liver, 
with bi-directional signalling between the gut microbiota and the liver having an impact on feeding behaviour and metabolic control [54].

\subsection{Immuno-Inflammatory Pathways}

Given the intricate links between the gut microbiota and the host immune system, it is perhaps not surprising that the immuno-inflammatory pathway/system represents a highly plausible means by which communications manifest between the gut microbiota and the host. Indeed, certain species of gut microbiota associate with changes in the inflammatory milieu of the host. One such example is the Gram-positive anaerobe Faecalibacterium prausnitzii, which associates with anti-inflammatory effects within the host. Possible mechanisms include the blockade of nuclear factor- $\mathrm{kB}$ activation with subsequent inhibited secretion of pro-inflammatory mediators [55-57]. The mechanisms by which Gram-positive anaerobes, such as Faecalibacterium prausnitzii, confer anti-inflammatory and metabolic benefits for the host may occur indirectly, through for example the production of metabolic by-products such as butyrate (a key SCFA). Indeed, there is evidence to support an association between gut microbiota-derived butyrate and improved energy metabolism in rodents [58]. Neuro-inflammation stimulated by translocated bacteria (in the context of dysbiosis and intestinal permeability), including activation of the innate immune system, may represent an important contributor to the pathogenesis of certain neurological and psychiatric conditions such as schizophrenia and other psychotic disorders [59].

\subsection{Gut Wall Integrity}

The gut wall forms the boundary between the gut microbiota and the host. As such, complex bi-directional communication between the gut microbiota and the host brain must either cross (or at least influence in some way) the gut wall. Such communications may occur either directly through the translocation of the microbiota (or some microbiota component) and/or their metabolic by-products, or indirectly through effects via the host immuno-inflammatory, autonomic or endocrine systems. Fascinatingly, the integrity of the gut wall may influence the inflammatory processes within the brain and neuropathology following traumatic brain injury (TBI) [60]. Bi-directional pathways exist in which structural and functional damage to the GI tract can occur following a head injury, which in turn influence the progression of neuropathology and neurodegeneration, including the development of post-TBI chronic traumatic encephalopathy [60]. The integrity of the gut wall may therefore represent a therapeutic target to mitigate the adverse neuropathological outcomes following TBI, to reduce the risk of development of psychiatric disease and psychosis and to promote healthy mental and emotional functioning.

Notably, there is protection of the gut wall itself by a layer of mucus (mucin) that acts as a first line of defence. Chassaing and colleagues explored the thickness of the colonic wall mucus layer in a human-based study by measuring the distance between the gut microbiota and the gut epithelial lining on colonic biopsies [61]. Interestingly, there was an inverse correlation between colonic mucus thickness and the metabolic measures of body mass index (BMI), $\mathrm{HbA1C}$ and fasting glucose levels [61]. Although causality cannot be proven, these data are consistent with the notion that mucus-mediated gut wall permeability influences overall metabolic health. Furthermore, gut microbiota play an important role in influencing the colonic wall mucus layer. For example, Akkermansia muciniphila is a mucin-degrading bacterium that may influence the colonic wall mucus layer [62]. Clarke and colleagues demonstrated a higher proportion of Akkermansia species within the gut microbiota of professional rugby players and controls who were also athletes and had a low BMI, compared with the gut microbiota from high BMI controls [63]. In a different study, levels of colonic Akkermansia muciniphila were reduced in adults with obesity and T2D [64]. The example of Akkermansia muciniphila is useful to illustrate the perils of considering one species of gut microbiota in isolation from the myriad of others. Akkermansia muciniphila degrades mucin, and therefore acting in isolation, it would likely impair the essential mucin colonic epithelial protective barrier [65-67]. However, 
Akkermansia muciniphila also converts intestinal mucin to propionic and acetic acid [68], and thereby engages in a symbiotic relationship with the host to provide essential nutrients that are accessible to other resident gut microbiota within the vicinity [64,69]. Many of these other microbiota may in turn have protective effects on the colonic mucin layer and impact on other microbiota and the host through a myriad of mechanisms [70]. Through such insights, future models of the gut microbiota and its interactions with the host should incorporate a more holistic perspective, with the promotion of interactions within the gut microbiota and between the gut microbiota and the host, rather than too much focus on the effects of individual species of microbiota on the host considered in isolation. It is only through the development of such complex models that we will truly understand the intricacies of how the gut microbiota interacts with itself and with its host.

To summarize this section, the microbiota-gut-brain axis forms an essential component for metabolic and overall health and wellbeing. The mechanisms implicated are complex and bi-directional and include effects of metabolic by-products of the gut microbiota, the incretin system, mitochondrial function, the HPA axis, autonomic signals, immuno-inflammatory pathways, liver signalling and gut wall integrity. Much of the current literature relies on association-based studies, rodent models and study of the effects of individual species of gut microbiota on the host in isolation. As such, the field of gut microbiota and its host interactions is in its infancy. We need to move beyond simply labelling species within the gut microbiota as 'good' or 'bad'. Rather, we need to develop a more sophisticated model whereby there is deserved consideration of the gut microbiota as a colony that interacts en masse with its host. Such a model would act as an expedient to the development of effective lifestyle measures to optimize the establishment and maintenance of a healthy gut microbiota, with health-promoting effects. Amongst such lifestyle measures, our diet plays an essential role, and so it is important to consider dietary effects on the gut microbiota.

\section{Dietary Influences on the Gut Microbiota}

Although multiple lifestyle factors contribute towards the establishment and maintenance of the gut microbiota, diet plays a major role. To corroborate this view, a fascinating archaeological study on teeth revealed significant changes in the human gut microbiota during periods of rapid dietary change amongst our human ancestors [71]. This included the transition from the hunter-gatherer Palaeolithic to the farming Neolithic eras around 10,000 years ago (with the adoption of a high-carbohydrate diet), and the beginning of the industrialized era around 200 years ago (with the adoption of a diet rich in processed flour and carbohydrates) [71]. Since the dawn of the industrialized era, Western diets have further changed, with a substantial reduction in the ingestion of dietary fibre derived primarily from unprocessed plant-based foods, mirrored by a reciprocal increase in the ingestion of ultra-highly processed foods that are often sterile, heavily laden with fats and carbohydrates and impoverished of dietary fibre [72]. Rodent-based studies reveal that changes in dietary macronutrient intake can consistently alter the gut microbiota within a single day [73]. Although many previously reported dietary studies in human cohorts had timeframes of weeks or months [74], with changes in a limited number of species within the gut microbiota $[75,76]$ or failure to demonstrate any significant diet-induced changes in the gut microbiota [77], more recent compelling data reveal changes in the gut microbiota composition resulting from short-term dietary changes [78]. In one of the most deeply phenotyped studies reported to date using metagenomic sequencing, there were significant associations between gut microbes and specific nutrients and food groups, driven particularly by healthy and diverse plant-based foods [79]. Furthermore, overall microbiome composition was predictive for multiple cardio-metabolic blood markers, suggesting the potential for future stratification of the gut microbiota as a predictor of future health and illness prior to the development of clinically manifesting disease [79].

Dietary studies in human participants are inherently difficult to conduct for a variety of reasons that include limitations in the accurate recording of dietary intake and the study 
of macronutrient changes in isolation from the rest of the diet and other lifestyle factors. Furthermore, diet-induced changes in the gut microbiota do not necessarily translate into changes in brain functioning or other host-related effects. Despite these caveats, it is important to consider the evidence for how individual macronutrients influence the human gut microbiota, including dietary fibres (plant-based diets) and dietary fats (animal-based diets), summarized in Table 1.

\subsection{Dietary Fibres}

Dietary fibres comprise two main groups: (i) complex carbohydrates (including digestible and non-digestible forms), and (ii) oligosaccharides [5]. Dietary fibres have an important influence on the composition of the gut microbiota and its fermentative metabolism [5]. Perhaps more than any other macronutrient, dietary fibres play an important role in the establishment and nurture of a healthy gut microbiota and the promotion of health and wellbeing [72].

\subsection{Complex Carbohydrates}

The ingestion of complex carbohydrates promotes bacterial growth favourable for health within the gut microbiota, including Bifidobacteria species (Bifidobacterium breve, Bifidobacterium longum and Bacteroides thetaiotaomicron) [80]. Whilst the ingestion of dietary fibre as complex carbohydrates normally includes a combination of both digestible (soluble) and non-digestible (insoluble) types, each has specific effects on the gut microbiota. The ingestion of digestible fibres associates with an increase in the proportion of Bacteroides species and butyrate-producing bacteria, such as Eubacterium rectale and Clostridium leptum $[81,82]$. Only a fraction of the diet remains undigested as complex carbohydrates when it reaches the colon, including plant cell wall polysaccharides, cellulose and resistant starches [83]. Using an anaerobic in vitro continuous flow system and faecal samples from human participants, Leitch and colleagues showed that the ingestion of non-digestible resistant starches was associated with an increased abundance of Ruminococcus species, Bifidobacterium adolescentis, Eubacterium rectale and Roseburia species [84]. An important insight from this study is that specific subsets of bacteria are likely the primary colonisers of particular insoluble substrates within the colon, but that the primary colonising species for each substrate may differ between each individual host [84]. Furthermore, data from a human-based study showed that resistant starches with a chemical cross-linking configuration influenced phylum-level changes within the gut microbiota, including an increase in the proportion of Bacteroides and Actinobacteria, and a reduction in the proportion of Firmicutes [85] 


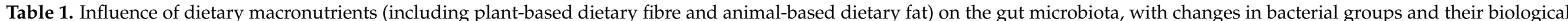
significance. LPS = Lipopolysaccharide; SCFA = Short Chain Fatty Acid.

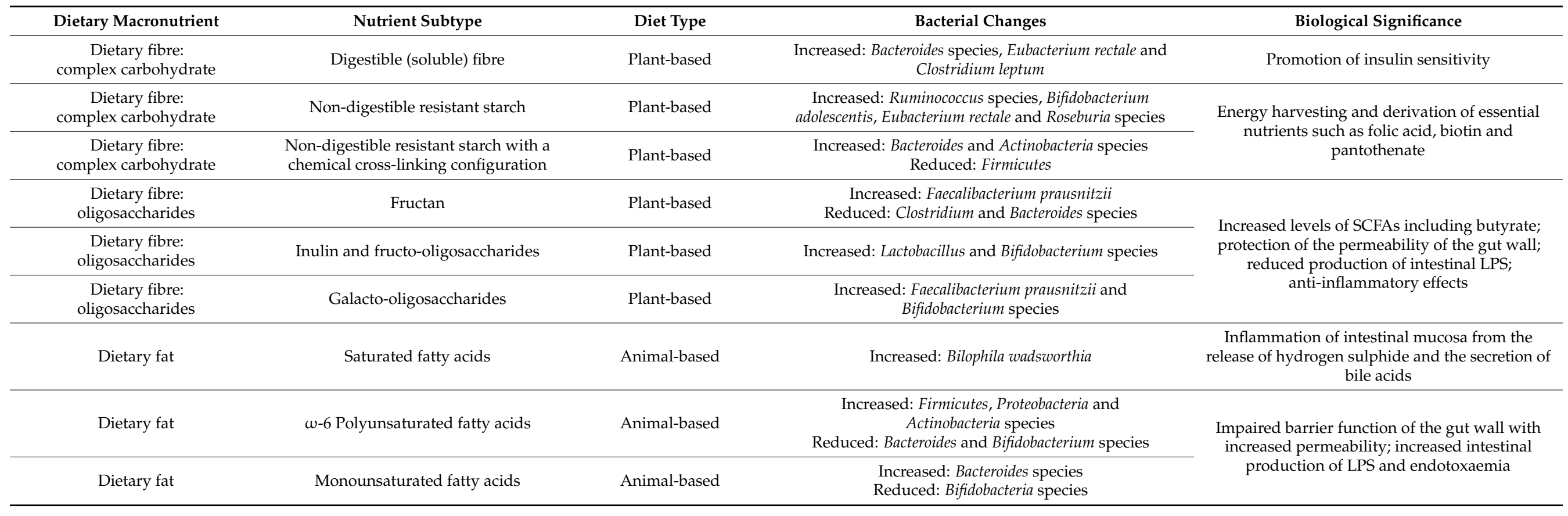


The ingestion of dietary fibre associates with health and wellbeing. The role of the gut microbiota in the mediation of the numerous health benefits of dietary fibre remains incompletely understood [72]. However, clear evidence implicates an important role for ingested non-digestible fibre in the derivation of certain nutrients and energy harvesting mediated by the gut microbiota in concert with intestinal digestive enzymes. These nutrients and released energy are then utilised by the host and other resident gut microbiota. Some examples of such gut microbiota-derived nutrients include vitamins like folic acid, biotin and pantothenate that are synthesized by Bacteroides, Eubacterium, Fusobacterium and Propionibacterium [86]. Of note, some species of gut microbiota compete with their host for certain nutrients. One example of such competition is Bacteroides thetaiotaomicron, which utilises vitamin B12 for its own needs. In one human-based study, a surface-exposed lipoprotein (BtuG) in Bacteroides thetaiotaomicron bound with great affinity to B12, with sequestration of B12 from intrinsic factor, thereby reducing the availability of vitamin B12 for absorption and utilisation by the host [87]. However, as outlined earlier, it is important to consider the impact of the gut microbiota on nutrient availability and energy harvesting from a colony derived perspective rather than the effects of individual species of microbiota in isolation. What is incontrovertible is that despite some competition with the host, the gut microbiota provides us with essential nutrients, without which our health would suffer. Furthermore, the ingestion of dietary fibre, particularly in its non-digestible form, provides an essential ingredient for this process to occur naturally.

\subsection{Oligosaccharides}

In addition to complex carbohydrates, the ingestion of oligosaccharides also influences the gut microbiota. In one microarray analysis, the ingestion of fructan was associated with a reduction in both Clostridium and Bacteroides species [88]. In another human-based study, fructan ingestion promoted the growth of butyrate-producing bacteria, such as Faecalibacterium prausnitzii [89]. Conversely, the ingestion of inulin and fructo-oligosaccharides appears to promote the growth of Lactobacillus and Bifidobacterium species [88]. Finally, human-based data reveal that the ingestion of galacto-oligosaccharides can stimulate the growth of Faecalibacterium prausnitzii and species of Bifidobacteria [90].

\subsection{Dietary Fats}

When considering the effects of dietary fat on the gut microbiota, it is important to clarify the type of model used (human vs. rodent) and the type of fatty acid assessed: (i) saturated fatty acid (SFA); (ii) monounsaturated fatty acid (MUFA); or (iii) polyunsaturated fatty acid (PUFA), of which there are two types ( $\omega-6$ and $\omega-3)$ [5,91]. It is much easier to regulate the dietary constituents of SFA, MUFA and PUFA in rodent models than in humans. Accordingly, most of the reported studies on the effects of these specific types of fatty acids on the gut microbiota stem from murine models. These include murinebased diets rich in SFAs that associate with the growth of delta-Proteobacteria, including Bilophila wadsworthia [92], and those high in w-6 PUFAs that associate with a reduction in the populations of Bacteroides whilst enriching populations of Firmicutes, Proteobacteria and Actinobacteria [93]. Indeed, murine-based studies also reveal that a high-fat diet results in dysbiosis, with a significant reduction in the numbers of Roseburia species [94].

Regarding human-based studies, Wu and colleagues demonstrated that a high-fat diet over a longer term was positively associated with an abundance of Bacteroides and Actinobacteria, but negatively associated with Firmicutes and Proteobacteria [77]. Interestingly, a high-fibre diet manifested opposite effects on the gut microbiota to those shown with a high-fat diet [77]. In a further human-based study, a high intake of MUFA associated with higher populations of Bacteroides and lower levels of Bifidobacteria species, whilst high dietary intake of $\omega-6$ PUFA also associated with a reduction in the population of Bifidobacteria [82].

Human-based high-fat diets tend to derive from animal-based diets (including meats, eggs and cheeses). One study reported on the rapid effects of predominantly plant-based 
and animal-based diets (with an abundance of fibre and fats, respectively) on the gut microbiota. Human participants $(\mathrm{n}=10)$ consumed each diet ad libitum for a period of five days [78]. For the high-fat, animal-based diet, data revealed a rapid change in the $\beta$-diversity of the gut microbiota (a measure of the difference between baseline and dietassociated gut microbiota) a single day after the diet reached the distal gut microbiota. This included significant changes in the abundance of 22 clusters of gut microbiota species [78]. Fascinatingly, the most abundant taxon amongst these clusters (including Bacteroides, Alistipes and Bilophila) exhibited bile-resistance, consistent with the association of high fat intake with the enhanced secretion of bile acids $[78,95]$. Furthermore, in addition to changes in $\beta$-diversity, there were also alterations in microbial metabolic activity for each diet, with the animal-based diet associated with a significant reduction in products of carbohydrate fermentation and an increase in the products of amino acid fermentation [78] Following the end of the animal-based diet, the gut microbiota reverted to its original structure within two days [78].

To summarize this sub-section, data from both rodent- and human-based studies reveal a myriad of influences of our diet on our gut microbiota. Although there are some clear health benefits from the ingestion of certain macronutrients (such as nondigestible fibre) and the derivation of essential nutrients, much of the available data simply report on associations of certain macronutrients with changes in the relative growth and abundance of particular bacterial species within the gut microbiota. However, some evidence extends beyond mere association between diet and gut bacterial species. An important example stems from a mouse model that reveals an association between the consumption of a high-fat diet with colonic inflammation. The underlying pathogenic pathway possibly involves the secretion of bile acids, which in turn promotes the growth of sulphite-reducing bacteria such as Bilophila wadsworth; the release of hydrogen sulphide then causes inflammation of the intestinal mucosa [92]. Interestingly, human-based studies also reveal an association between a high-fat diet and low-grade inflammation within the gut, including the promotion of the growth of Bilophila wadsworth [78].

In addition to localized inflammation, it is also important to consider the effects of dietary macronutrients on gut permeability. In this regard, Bifidobacteria species appear to protect the permeability of the gut wall through improved barrier function and reduced production of intestinal LPS [96]. Conversely, the promotion of certain Gram-negative bacteria, such as Enterobacteriaceae, through high-fat diets can increase intestinal levels of LPS [97]. LPS can activate Toll-like receptor 4 (TLR-4) signalling, which is implicated in the pathogenesis of glioblastoma multiforme [98]. Furthermore, the ingestion of high-protein diets can promote a localized inflammatory response within the gut, resulting from the production of toxic metabolites stimulated by certain bacterial enzymes [99]. Therefore, from a holistic perspective, typical Western diets (which are high in both protein and fats and impoverished of fibre) promote intestinal dysbiosis with consequently impaired protection of gut wall permeability and a localized inflammatory response [100]. The combination of increased gut wall permeability, colonic inflammation and enhanced colonic production of LPS results in chronic endotoxaemia with excessive bacterial wall LPS present within the circulation. This, in turn, provokes systemic low-grade inflammation and ultimately metabolic dysfunction that underlies much of the modern-day chronic illness burden [101].

\section{Conclusions and Future Directions}

We can perhaps think of the gut microbiota as the last 'organ' discovered in the human body. There are, of course, many reasons why the gut microbiota would not fit our conventional view of an organ. Firstly, the gut microbiota technically reside outside of the body, and therefore from a purist perspective, we cannot consider this as part of the body as such. Furthermore, the gut microbiota are composed of prokaryotic cells that are alien, albeit very distantly related, to the host. Perhaps our main objection though is that organs have a supremely refined, highly ordered and organized structure that enables 
optimal performance of some vital function. The gut microbiota, in contrast, are perhaps the antithesis to what one would define as 'highly ordered and organized'. However, if we re-define an organ as a collection of cells that fulfils some vital role for the body and which communicates with other organs through physiological pathways, the gut microbiota has as much right to be on that list as any other conventional organ. The gut microbiota indeed fulfils functions that are vital for health and wellbeing, and dysbiosis underlies many chronic illnesses through important and complex pathogenic pathways [102]. As such, the gut microbiota are central to normal physiological function [103] and should, in our view, be considered as an organ in its own right, albeit an externalised organ and one formed of foreign cells. As with any organ, functionality only becomes apparent when considered as a whole. Just as focused attention on a single cardiomyocyte provides little insight into the function of the heart, so too does attention on a single species from the gut microbiota limit our understanding of the functioning of the gut microbiota as a whole colony. Similarly, just as the cells within an organ function together as a group to benefit the entire organism, so too do individual microbiota within the gut interact as a colony in complex ways, both with each other and with the host. Therefore, future studies should focus more on the colony derived effects of the gut microbiota both within itself and with the host.

Our co-evolution with our microbial and viral environments has, in some cases, transitioned beyond mere symbiosis to unity. Examples include the evolution of the eukaryotic cell with the origin of mitochondria, and the striking observation that between 5-8\% of the human genome derives from viral sequences similar to infectious retroviruses [104]. However, our relationship with our gut microbiota remains symbiotic, with a key role for the brain. From an evolutionary perspective, we can understand the relevance of the mechanisms that interlink the brain and the gut microbiota [105]. Given the central control of appetite, key metabolic processes and eating behaviours [106], it is no surprise that elements of the microbiota-gut-brain axis feature prominently amongst the identified gut microbiota-host interactions. In short, our gut microbiota have co-evolved with us to manipulate our brains to their own advantage, and vice versa. Elucidation of the actual mechanisms implicated, and the influence of both microbiota- and host-related factors, remains an important challenge for the future.

Although numerous lifestyle factors, including sleep, physical activity and stress, may influence the gut microbiota in important ways [107,108], it is beyond the scope of this concise review to provide such details. Instead, we focus on the effects of dietary macronutrients on the gut microbiota. Diet is inherently difficult to study in humans for a variety of reasons, not least due to the difficulty of studying the effects of a single macronutrient in isolation, and problems with the accuracy of self-recall regarding dietary intake [72]. Furthermore, evidence to support clear effects of a particular macronutrient on the gut microbiota signature does not prove any potential downstream effects on the host. Future studies should explore the effects of dietary and other lifestyle factors on not just individual microbes within the microbiota, but the microbiota colony as a whole, in addition to the interactions of the gut microbiota with the host. Such studies will provide clear insights into how best to optimise our own diets and lifestyles to establish, maintain and nurture a healthy gut microbiota. These insights will provide a basis for future guidelines on healthy living and healthy ageing.

Our modern-day diets are vastly different from what our hominid ancestors would have eaten [109]. For one, ultra-highly processed foods have only been available to us very recently [110], and is something that our gut microbiota have never experienced previously. Furthermore, our modern-day world, including our food, is highly sterilized compared to the evolutionary norm. Whilst such sterilization has helped to address infections and infestations, our gut microbiota have also needed to adapt rapidly. It is possible that a reduction in the replenishing effects of ingested microorganisms (present within natural food sources), may be harmful to us. Indeed, in the study outlined by David and colleagues, bacteria in common fermented foods from both plant- and animal-based diets (such as lactic acid bacteria within cheese and cured meats), reached the gut following ingestion, 
and were detectable on sequencing analysis [78]. Therefore, the introduction of foreign microorganisms within our food may represent an important means by which our gut microbiota addresses its constant need for replenishment.

Finally, in our quest to explore the gut microbiota and its effects on us, it is important to consider its modification through means alternate to dietary change, such as faecal transplantation. Currently, faecal transplantation has only one indication within the National Health Service (NHS) in the UK: in the management of patients with intractable colonic colonisation with Clostridium difficile [111]. Evidence from murine models reveals that faecal transplantation can result in changes in both body weight and metabolic status [112]. Human studies on faecal transplantation show improvements in glucose tolerance but have not yet demonstrated effective weight loss in recipients with obesity $[112,113]$. The inherent complexity of the gut microbiota, its interaction with the host and its uniqueness to each individual pose significant challenges for its investigation. Rodent-based studies provide compelling data and proof-of-concept that modification of the faecal microbiota translates into metabolic transformation within the host. Whilst caution is required in the translation of rodent to human-based data, such evidence should enthuse and inspire us to explore the therapeutic potential of the manipulation of the gut microbiota in humans to optimize health and wellbeing through both dietary and faecal modifications.

Funding: This research received no external funding.

Conflicts of Interest: None of the authors have any conflict of interest.

\section{References}

1. Mayer, E.A.; Tillisch, K.; Gupta, A. Gut/brain axis and the microbiota. J. Clin. Investig. 2015, 125, 926-938. [CrossRef]

2. Sender, R.; Fuchs, S.; Milo, R. Revised Estimates for the Number of Human and Bacteria Cells in the Body. PLoS Biol. 2016, 14, e1002533. [CrossRef]

3. Mueller, N.T.; Bakacs, E.; Combellick, J.; Grigoryan, Z.; Dominguez-Bello, M.G. The infant microbiome development: Mom matters. Trends Mol. Med. 2015, 21, 109-117. [CrossRef]

4. Gaboriau-Routhiau, V.; Cerf-Bensussan, N. Gut microbiota and development of the immune system. Med. Sci. 2016, 32, 961-967.

5. Bibbo, S.; Ianiro, G.; Giorgio, V.; Scaldaferri, F.; Masucci, L.; Gasbarrini, A.; Cammarota, G. The role of diet on gut microbiota composition. Eur Rev. Med. Pharm. Sci. 2016, 20, 4742-4749.

6. Lozupone, C.A.; Stombaugh, J.I.; Gordon, J.I.; Jansson, J.K.; Knight, R. Diversity, stability and resilience of the human gut microbiota. Nature 2012, 489, 220-230. [CrossRef] [PubMed]

7. Xiang, Q.; Wu, X.; Pan, Y.; Wang, L.; Cui, C.; Guo, Y.; Zhu, L.; Peng, J.; Wei, H. Early-Life Intervention Using Fecal Microbiota Combined with Probiotics Promotes Gut Microbiota Maturation, Regulates Immune System Development, and Alleviates Weaning Stress in Piglets. Int. J. Mol. Sci. 2020, 21, 503. [CrossRef] [PubMed]

8. Kim, T.T.; Parajuli, N.; Sung, M.M.; Bairwa, S.C.; Levasseur, J.; Soltys, C.-L.M.; Wishart, D.S.; Madsen, K.; Schertzer, J.D.; Dyck, J.R. Fecal transplant from resveratrol-fed donors improves glycaemia and cardiovascular features of the metabolic syndrome in mice. Am. J. Physiol.-Endocrinol. Metab. 2018, 315, E511-E519. [CrossRef] [PubMed]

9. Gérard, P. Gut microbiome and obesity. How to prove causality? Ann. Am. Thorac. Soc. 2017, 14, S354-S356. [CrossRef]

10. Zhang, L.; Bahl, M.I.; Roager, H.M.; Fonvig, C.E.; Hellgren, L.I.; Frandsen, H.L.; Pedersen, O.; Holm, J.-C.; Hansen, T.; Licht, T.R. Environmental spread of microbes impacts the development of metabolic phenotypes in mice transplanted with microbial communities from humans. ISME J. 2017, 11, 676-690. [CrossRef]

11. Clavel, T.; Desmarchelier, C.; Haller, D.; Gérard, P.; Rohn, S.; Lepage, P.; Daniel, H. Intestinal microbiota in metabolic diseases: From bacterial community structure and functions to species of pathophysiological relevance. Gut Microbes 2014, 5, 544-551. [CrossRef] [PubMed]

12. Guirro, M.; Costa, A.; Gual-Grau, A.; Herrero, P.; Torrell, H.; Canela, N.; Arola, L. Effects from diet-induced gut microbiota dysbiosis and obesity can be ameliorated by fecal microbiota transplantation: A multiomics approach. PLoS ONE 2019, 14, e218143. [CrossRef] [PubMed]

13. Butel, M.J.; Waligora-Dupriet, A.J.; Wydau-Dematteis, S. The developing gut microbiota and its consequences for health. J. Dev. Orig. Health. Dis. 2018, 9, 590-597. [CrossRef]

14. Oduro-Donkor, D.; Turner, M.C.; Farnaud, S.; Renshaw, D.; Kyrou, I.; Hanson, P.; Hattersley, J.; Weickert, M.O.; Menon, V.; Randeva, H.S.; et al. Modification of fecal microbiota as a mediator of effective weight loss and metabolic benefits following bariatric surgery. Expert Rev. Endocrinol. Metab. 2020, 15, 363-373. [CrossRef]

15. Caputi, V.; Giron, M.C. Microbiome-Gut-Brain Axis and Toll-Like Receptors in Parkinson's Disease. Int. J. Mol. Sci. 2018, 19, 1689. [CrossRef] [PubMed] 
16. Fattorusso, A.; Di Genova, L.; Dell'Isola, G.B.; Mencaroni, E.; Esposito, S. Autism Spectrum Disorders and the Gut Microbiota. Nutrients 2019, 11, 521. [CrossRef] [PubMed]

17. Guo, R.; Chen, L.H.; Xing, C.; Liu, T. Pain regulation by gut microbiota: Molecular mechanisms and therapeutic potential. Br. J. Anaesth. 2019, 123, 637-654. [CrossRef]

18. Huang, T.T.; Lai, J.B.; Du, Y.L.; Xu, Y.; Ruan, L.M.; Hu, S.H. Current Understanding of Gut Microbiota in Mood Disorders: An Update of Human Studies. Front. Genet. 2019, 10, 98. [CrossRef]

19. Bravo, J.A.; Forsythe, P.; Chew, M.V.; Escaravage, E.; Savignac, H.M.; Dinan, T.G.; Bienenstock, J.; Cryan, J.F. Ingestion of Lactobacillus strain regulates emotional behavior and central GABA receptor expression in a mouse via the vagus nerve. Proc. Natl. Acad. Sci. USA 2011, 108, 16050-16055. [CrossRef]

20. Bercik, P.; Denou, E.; Collins, J.; Jackson, W.; Lu, J.; Jury, J.; Deng, Y.; Blennerhassett, P.; Macri, J.; McCoy, K.D.; et al. The intestinal microbiota affect central levels of brain-derived neurotropic factor and behavior in mice. Gastroenterology 2011, 141, 599-609. [CrossRef]

21. Neufeld, K.A.; Kang, N.; Bienenstock, J.; Foster, J.A. Effects of intestinal microbiota on anxiety-like behavior. Commun. Integr. Biol. 2011, 4, 492-494. [CrossRef]

22. Clarke, G.; Grenham, S.; Scully, P.; Fitzgerald, P.; Moloney, R.D.; Shanahan, F.; Dinan, T.G.; Cryan, J.F. The microbiome-gut-brain axis during early life regulates the hippocampal serotonergic system in a sex-dependent manner. Mol. Psychiatry 2013, 18, 666-673. [CrossRef]

23. Oliphant, K.; Allen-Vercoe, E. Macronutrient metabolism by the human gut microbiome: Major fermentation by-products and their impact on host health. Microbiome 2019, 7, 91. [CrossRef]

24. Wikoff, W.R.; Anfora, A.T.; Liu, J.; Schultz, P.G.; Lesley, S.A.; Peters, E.C.; Siuzdak, G. Metabolomics analysis reveals large effects of gut microflora on mammalian blood metabolites. Proc. Natl. Acad. Sci. USA 2009, 106, 3698-3703. [CrossRef]

25. Clark, A.; Mach, N. The Crosstalk between the Gut Microbiota and Mitochondria during Exercise. Front. Physiol. 2017, 8, 319. [CrossRef]

26. Sanmiguel, C.P.; Jacobs, J.; Gupta, A.; Ju, T.; Stains, J.; Coveleskie, K.; Lagishetty, V.; Balioukova, A.; Chen, Y.; Dutson, E. Surgically induced changes in gut microbiome and hedonic eating as related to weight loss: Preliminary findings in obese women undergoing bariatric surgery. Psychosom. Med. 2017, 79, 880. [CrossRef] [PubMed]

27. Yano, J.M.; Yu, K.; Donaldson, G.P.; Shastri, G.G.; Ann, P.; Ma, L.; Nagler, C.R.; Ismagilov, R.F.; Mazmanian, S.K.; Hsiao, E.Y. Indigenous bacteria from the gut microbiota regulate host serotonin biosynthesis. Cell 2015, 161, 264-276. [CrossRef] [PubMed]

28. Haghikia, A.; Jörg, S.; Duscha, A.; Berg, J.; Manzel, A.; Waschbisch, A.; Hammer, A.; Lee, D.-H.; May, C.; Wilck, N. Dietary fatty acids directly impact central nervous system autoimmunity via the small intestine. Immunity 2015, 43, 817-829. [CrossRef] [PubMed]

29. Lu, Y.; Fan, C.; Li, P.; Lu, Y.; Chang, X.; Qi, K. Short Chain Fatty Acids Prevent High-fat-diet-induced Obesity in Mice by Regulating G Protein-coupled Receptors and Gut Microbiota. Sci. Rep. 2016, 6, 37589. [CrossRef] [PubMed]

30. Li, X.; Shimizu, Y.; Kimura, I. Gut microbial metabolite short-chain fatty acids and obesity. Biosci. Microbiotafood Health. 2017, 36, 135-140. [CrossRef] [PubMed]

31. Samuel, B.S.; Shaito, A.; Motoike, T.; Rey, F.E.; Backhed, F.; Manchester, J.K.; Hammer, R.E.; Williams, S.C.; Crowley, J.; Yanagisawa, M. Effects of the gut microbiota on host adiposity are modulated by the short-chain fatty-acid binding $\mathrm{G}$ protein-coupled receptor, Gpr41. Proc. Natl. Acad. Sci. USA 2008, 105, 16767-16772. [CrossRef] [PubMed]

32. Tolhurst, G.; Heffron, H.; Lam, Y.S.; Parker, H.E.; Habib, A.M.; Diakogiannaki, E.; Cameron, J.; Grosse, J.; Reimann, F.; Gribble, F.M. Short-chain fatty acids stimulate glucagon-like peptide-1 secretion via the G-protein-coupled receptor FFAR2. Diabetes 2012, 61, 364-371. [CrossRef]

33. Alexander, C.; Swanson, K.S.; Fahey, G.C.; Garleb, K.A. Perspective: Physiologic Importance of Short-Chain Fatty Acids from Nondigestible Carbohydrate Fermentation. Adv. Nutr. 2019, 10, 576-589. [CrossRef]

34. Chambers, E.S.; Viardot, A.; Psichas, A.; Morrison, D.J.; Murphy, K.G.; Zac-Varghese, S.E.; MacDougall, K.; Preston, T.; Tedford, C.; Finlayson, G.S. Effects of targeted delivery of propionate to the human colon on appetite regulation, body weight maintenance and adiposity in overweight adults. Gut 2015, 64, 1744-1754. [CrossRef]

35. Weickert, M.O.; Arafat, A.M.; Blaut, M.; Alpert, C.; Becker, N.; Leupelt, V.; Rudovich, N.; Mohlig, M.; Pfeiffer, A.F. Changes in dominant groups of the gut microbiota do not explain cereal-fiber induced improvement of whole-body insulin sensitivity. Nutr. Metab. (Lond.) 2011, 8, 90. [CrossRef]

36. Weickert, M.O. High fiber intake, dietary protein, and prevention of type 2 diabetes. Expert Rev. Endocrinol. Metab. 2018, 13, 223-224. [CrossRef]

37. Weickert, M.O.; Roden, M.; Isken, F.; Hoffmann, D.; Nowotny, P.; Osterhoff, M.; Blaut, M.; Alpert, C.; Gogebakan, O.; Bumke-Vogt, C.; et al. Effects of supplemented isoenergetic diets differing in cereal fiber and protein content on insulin sensitivity in overweight humans. Am. J. Clin. Nutr. 2011, 94, 459-471. [CrossRef]

38. Weickert, M.O.; Spranger, J.; Holst, J.J.; Otto, B.; Koebnick, C.; Mohlig, M.; Pfeiffer, A.F. Wheat-fibre-induced changes of postprandial peptide $\mathrm{YY}$ and ghrelin responses are not associated with acute alterations of satiety. Br. J. Nutr. 2006, 96, 795-798. [CrossRef] 
39. Pfluger, P.T.; Kampe, J.; Castaneda, T.R.; Vahl, T.; D’Alessio, D.A.; Kruthaupt, T.; Benoit, S.C.; Cuntz, U.; Rochlitz, H.J.; Moehlig, M.; et al. Effect of human body weight changes on circulating levels of peptide YY and peptide YY3-36. J. Clin. Endocrinol. Metab. 2007, 92, 583-588. [CrossRef]

40. Weickert, M.O.; Pfeiffer, A.F.H. Impact of Dietary Fiber Consumption on Insulin Resistance and the Prevention of Type 2 Diabetes. J. Nutr. 2018, 148, 7-12. [CrossRef]

41. Weickert, M.O.; Pfeiffer, A.F. Metabolic effects of dietary fiber consumption and prevention of diabetes. J. Nutr. 2008, 138, 439-442. [CrossRef]

42. McNeil, N.I. The contribution of the large intestine to energy supplies in man. Am. J. Clin. Nutr 1984, 39, 338-342. [CrossRef] [PubMed]

43. Isken, F.; Klaus, S.; Osterhoff, M.; Pfeiffer, A.F.; Weickert, M.O. Effects of long-term soluble vs. insoluble dietary fiber intake on high-fat diet-induced obesity in C57BL/6J mice. J. Nutr. Biochem. 2010, 21, 278-284. [CrossRef]

44. Pfeiffer, A.F.; Rudovich, N.; Weickert, M.O.; Isken, F. Role of the gut Peptide glucose-induced insulinomimetic Peptide in energy balance. Results Probl. Cell Differ. 2010, 52, 183-188.

45. Isken, F.; Weickert, M.O.; Tschop, M.H.; Nogueiras, R.; Mohlig, M.; Abdelrahman, A.; Klaus, S.; Thorens, B.; Pfeiffer, A.F. Metabolic effects of diets differing in glycaemic index depend on age and endogenous glucose-dependent insulinotrophic polypeptide in mice. Diabetologia 2009, 52, 2159-2168. [CrossRef]

46. Isken, F.; Pfeiffer, A.F.; Nogueiras, R.; Osterhoff, M.A.; Ristow, M.; Thorens, B.; Tschop, M.H.; Weickert, M.O. Deficiency of glucose-dependent insulinotropic polypeptide receptor prevents ovariectomy-induced obesity in mice. Am. J. Physiol. Endocrinol. Metab. 2008, 295, E350-E355. [CrossRef] [PubMed]

47. Ramirez-Perez, O.; Cruz-Ramon, V.; Chinchilla-Lopez, P.; Mendez-Sanchez, N. The Role of the Gut Microbiota in Bile Acid Metabolism. Ann. Hepatol. 2017, 16, S21-S26. [CrossRef]

48. Jia, W.; Xie, G.; Jia, W. Bile acid-microbiota crosstalk in gastrointestinal inflammation and carcinogenesis. Nat. Rev. Gastroenterol. Hepatol. 2018, 15, 111-128. [CrossRef]

49. Weickert, M.O.; Hattersley, J.G.; Kyrou, I.; Arafat, A.M.; Rudovich, N.; Roden, M.; Nowotny, P.; von Loeffelholz, C.; Matysik, S.; Schmitz, G.; et al. Effects of supplemented isoenergetic diets varying in cereal fiber and protein content on the bile acid metabolic signature and relation to insulin resistance. Nutr. Diabetes 2018, 8, 11. [CrossRef]

50. Serena, C.; Ceperuelo-Mallafré, V.; Keiran, N.; Queipo-Ortuño, M.I.; Bernal, R.; Gomez-Huelgas, R.; Urpi-Sarda, M.; Sabater, M.; Pérez-Brocal, V.; Andrés-Lacueva, C. Elevated circulating levels of succinate in human obesity are linked to specific gut microbiota. ISME J. 2018, 12, 1642-1657. [CrossRef]

51. Chen, J.; Vitetta, L. Mitochondria could be a potential key mediator linking the intestinal microbiota to depression. J. Cell Biochem. 2020, 121, 17-24. [CrossRef]

52. Nishino, R.; Mikami, K.; Takahashi, H.; Tomonaga, S.; Furuse, M.; Hiramoto, T.; Aiba, Y.; Koga, Y.; Sudo, N. Commensal microbiota modulate murine behaviors in a strictly contamination-free environment confirmed by culture-based methods. Neurogastroenterol. Motil. 2013, 25, 521-528. [CrossRef]

53. Misiak, B.; Loniewski, I.; Marlicz, W.; Frydecka, D.; Szulc, A.; Rudzki, L.; Samochowiec, J. The HPA axis dysregulation in severe mental illness: Can we shift the blame to gut microbiota? Prog Neuropsychopharmacol. Biol. Psychiatry 2020, 102, 109951. [CrossRef]

54. Ringseis, R.; Gessner, D.K.; Eder, K. The Gut-Liver Axis in the Control of Energy Metabolism and Food Intake in Animals. Annu. Rev. Anim. Biosci. 2020, 8, 295-319. [CrossRef]

55. Remely, M.; Hippe, B.; Zanner, J.; Aumueller, E.; Brath, H.; Haslberger, G.A. Gut microbiota of obese, type 2 diabetic individuals is enriched in Faecalibacterium prausnitzii, Akkermansia muciniphila and Peptostreptococcus anaerobius after weight loss. Endocr. Metab. Immune Disord.-Drug Targets (Former. Curr. Drug Targets-Immuneendocr. Metab. Disord.) 2016, 16, 99-106. [CrossRef]

56. Furet, J.-P.; Kong, L.-C.; Tap, J.; Poitou, C.; Basdevant, A.; Bouillot, J.-L.; Mariat, D.; Corthier, G.; Doré, J.; Henegar, C. Differential adaptation of human gut microbiota to bariatric surgery-induced weight loss: Links with metabolic and low-grade inflammation markers. Diabetes 2010, 59, 3049-3057. [CrossRef]

57. Graessler, J.; Qin, Y.; Zhong, H.; Zhang, J.; Licinio, J.; Wong, M.-L.; Xu, A.; Chavakis, T.; Bornstein, A.; Ehrhart-Bornstein, M. Metagenomic sequencing of the human gut microbiome before and after bariatric surgery in obese patients with type 2 diabetes: Correlation with inflammatory and metabolic parameters. Pharm. J. 2013, 13, 514-522. [CrossRef]

58. Li, Z.; Yi, C.X.; Katiraei, S.; Kooijman, S.; Zhou, E.; Chung, C.K.; Gao, Y.; van den Heuvel, J.K.; Meijer, O.C.; Berbee, J.F.P.; et al. Butyrate reduces appetite and activates brown adipose tissue via the gut-brain neural circuit. Gut 2018, 67, 1269-1279. [CrossRef]

59. Caso, J.R.; Balanza-Martinez, V.; Palomo, T.; Garcia-Bueno, B. The Microbiota and Gut-Brain Axis: Contributions to the Immunopathogenesis of Schizophrenia. Curr. Pharm. Des. 2016, 22, 6122-6133. [CrossRef]

60. Sundman, M.H.; Chen, N.K.; Subbian, V.; Chou, Y.H. The bidirectional gut-brain-microbiota axis as a potential nexus between traumatic brain injury, inflammation, and disease. Brain Behav. Immun. 2017, 66, 31-44. [CrossRef]

61. Chassaing, B.; Raja, S.M.; Lewis, J.D.; Srinivasan, S.; Gewirtz, A.T. Colonic microbiota encroachment correlates with dysglycemia in humans. Cell. Mol. Gastroenterol. Hepatol. 2017, 4, 205-221. [CrossRef]

62. Derrien, M.; Vaughan, E.E.; Plugge, C.M.; de Vos, W.M. Akkermansia muciniphila gen. nov.; sp. nov.; a human intestinal mucin-degrading bacterium. Int. J. Syst. Evol. Microbiol. 2004, 54, 1469-1476. [CrossRef]

63. Clarke, S.F.; Murphy, E.F.; O'Sullivan, O.; Lucey, A.J.; Humphreys, M.; Hogan, A.; Hayes, P.; O'Reilly, M.; Jeffery, I.B.; Wood-Martin, R. Exercise and associated dietary extremes impact on gut microbial diversity. Gut 2014, 63, 1913-1920. [CrossRef] 
64. de Vos, W.M. Microbe Profile: Akkermansia muciniphila: A conserved intestinal symbiont that acts as the gatekeeper of our mucosa. Microbiology 2017, 163, 646-648. [CrossRef]

65. Derrien, M.; Belzer, C.; de Vos, W.M. Akkermansia muciniphila and its role in regulating host functions. Microb. Pathog. 2017, 106, 171-181. [CrossRef] [PubMed]

66. Geerlings, S.Y.; Kostopoulos, I.; de Vos, W.M.; Belzer, C. Akkermansia muciniphila in the Human Gastrointestinal Tract: When, Where, and How? Microorganisms 2018, 6, 75. [CrossRef]

67. Zhou, J.C.; Zhang, X.W. Akkermansia muciniphila: A promising target for the therapy of metabolic syndrome and related diseases. Chin. J. Nat. Med. 2019, 17, 835-841. [CrossRef]

68. Van Herreweghen, F.; De Paepe, K.; Roume, H.; Kerckhof, F.M.; Van de Wiele, T. Mucin degradation niche as a driver of microbiome composition and Akkermansia muciniphila abundance in a dynamic gut model is donor independent. FEMS Microbiol. Ecol. 2018, 94. [CrossRef]

69. Belzer, C.; Chia, L.W.; Aalvink, S.; Chamlagain, B.; Piironen, V.; Knol, J.; de Vos, W.M. Microbial Metabolic Networks at the Mucus Layer Lead to Diet-Independent Butyrate and Vitamin B12 Production by Intestinal Symbionts. mBio 2017, 8, e00770-17. [CrossRef]

70. Paone, P.; Cani, P.D. Mucus barrier, mucins and gut microbiota: The expected slimy partners? Gut 2020, 69, 2232-2243. [CrossRef]

71. Adler, C.J.; Dobney, K.; Weyrich, L.S.; Kaidonis, J.; Walker, A.W.; Haak, W.; Bradshaw, C.J.; Townsend, G.; Soltysiak, A.; Alt, K.W.; et al. Sequencing ancient calcified dental plaque shows changes in oral microbiota with dietary shifts of the Neolithic and Industrial revolutions. Nat. Genet. 2013, 45, 450-455. [CrossRef]

72. Barber, T.M.; Kabisch, S.; Pfeiffer, A.F.H.; Weickert, M.O. The Health Benefits of Dietary Fibre. Nutrients 2020, 12, 3209. [CrossRef]

73. Faith, J.J.; McNulty, N.P.; Rey, F.E.; Gordon, J.I. Predicting a human gut microbiota's response to diet in gnotobiotic mice. Science 2011, 333, 101-104. [CrossRef]

74. Ley, R.E.; Turnbaugh, P.J.; Klein, S.; Gordon, J.I. Microbial ecology: Human gut microbes associated with obesity. Nature 2006, 444, 1022-1023. [CrossRef] [PubMed]

75. Duncan, S.H.; Belenguer, A.; Holtrop, G.; Johnstone, A.M.; Flint, H.J.; Lobley, G.E. Reduced dietary intake of carbohydrates by obese subjects results in decreased concentrations of butyrate and butyrate-producing bacteria in feces. Appl. Env. Microbiol. 2007, 73, 1073-1078. [CrossRef]

76. Walker, A.W.; Ince, J.; Duncan, S.H.; Webster, L.M.; Holtrop, G.; Ze, X.; Brown, D.; Stares, M.D.; Scott, P.; Bergerat, A.; et al. Dominant and diet-responsive groups of bacteria within the human colonic microbiota. ISME J. 2011, 5, 220-230. [CrossRef] [PubMed]

77. Wu, G.D.; Chen, J.; Hoffmann, C.; Bittinger, K.; Chen, Y.Y.; Keilbaugh, S.A.; Bewtra, M.; Knights, D.; Walters, W.A.; Knight, R.; et al. Linking long-term dietary patterns with gut microbial enterotypes. Science 2011, 334, 105-108. [CrossRef]

78. David, L.A.; Maurice, C.F.; Carmody, R.N.; Gootenberg, D.B.; Button, J.E.; Wolfe, B.E.; Ling, A.V.; Devlin, A.S.; Varma, Y.; Fischbach, M.A.; et al. Diet rapidly and reproducibly alters the human gut microbiome. Nature 2014, 505, 559-563. [CrossRef] [PubMed]

79. Asnicar, F.; Berry, S.E.; Valdes, A.M.; Nguyen, L.H.; Piccinno, G.; Drew, D.A.; Leeming, E.; Gibson, R.; Le Roy, C.; Khatib, H.A.; et al. Microbiome connections with host metabolism and habitual diet from 1,098 deeply phenotyped individuals. Nat. Med. 2021, 27, 321-332. [CrossRef] [PubMed]

80. Pokusaeva, K.; Fitzgerald, G.F.; van Sinderen, D. Carbohydrate metabolism in Bifidobacteria. Genes Nutr. 2011, 6, 285-306. [CrossRef]

81. Louis, P.; Scott, K.P.; Duncan, S.H.; Flint, H.J. Understanding the effects of diet on bacterial metabolism in the large intestine. J. Appl. Microbiol. 2007, 102, 1197-1208. [CrossRef] [PubMed]

82. Simoes, C.D.; Maukonen, J.; Kaprio, J.; Rissanen, A.; Pietilainen, K.H.; Saarela, M. Habitual dietary intake is associated with stool microbiota composition in monozygotic twins. J. Nutr. 2013, 143, 417-423. [CrossRef] [PubMed]

83. Flint, H.J. The impact of nutrition on the human microbiome. Nutr Rev. 2012, 70 (Suppl. 1), S10-S13. [CrossRef]

84. Leitch, E.C.; Walker, A.W.; Duncan, S.H.; Holtrop, G.; Flint, H.J. Selective colonization of insoluble substrates by human faecal bacteria. Env. Microbiol. 2007, 9, 667-679. [CrossRef] [PubMed]

85. Martinez, I.; Kim, J.; Duffy, P.R.; Schlegel, V.L.; Walter, J. Resistant starches types 2 and 4 have differential effects on the composition of the fecal microbiota in human subjects. PLoS ONE 2010, 5, e15046. [CrossRef]

86. Hill, M. Intestinal flora and endogenous vitamin synthesis. Eur. J. Cancer Prev. Off. J. Eur. Cancer Prev. Organ. (ECP) 1997, 6, S43-S45. [CrossRef] [PubMed]

87. Wexler, A.G.; Schofield, W.B.; Degnan, P.H.; Folta-Stogniew, E.; Barry, N.A.; Goodman, A.L. Human gut Bacteroides capture vitamin B12 via cell surface-exposed lipoproteins. Elife 2018, 7, e37138. [CrossRef]

88. Scott, K.P.; Martin, J.C.; Chassard, C.; Clerget, M.; Potrykus, J.; Campbell, G.; Mayer, C.D.; Young, P.; Rucklidge, G.; Ramsay, A.G.; et al. Substrate-driven gene expression in Roseburia inulinivorans: Importance of inducible enzymes in the utilization of inulin and starch. Proc. Natl. Acad. Sci. USA 2011, 108, 4672-4679. [CrossRef]

89. Ramirez-Farias, C.; Slezak, K.; Fuller, Z.; Duncan, A.; Holtrop, G.; Louis, P. Effect of inulin on the human gut microbiota: Stimulation of Bifidobacterium adolescentis and Faecalibacterium prausnitzii. Br. J. Nutr. 2009, 101, 541-550. [CrossRef]

90. Walton, G.E.; van den Heuvel, E.G.; Kosters, M.H.; Rastall, R.A.; Tuohy, K.M.; Gibson, G.R. A randomised crossover study investigating the effects of galacto-oligosaccharides on the faecal microbiota in men and women over 50 years of age. Br. J. Nutr. 2012, 107, 1466-1475. [CrossRef] 
91. Huang, E.Y.; Devkota, S.; Moscoso, D.; Chang, E.B.; Leone, V.A. The role of diet in triggering human inflammatory disorders in the modern age. Microbes. Infect. 2013, 15, 765-774. [CrossRef]

92. Devkota, S.; Wang, Y.; Musch, M.W.; Leone, V.; Fehlner-Peach, H.; Nadimpalli, A.; Antonopoulos, D.A.; Jabri, B.; Chang, E.B. Dietary-fat-induced taurocholic acid promotes pathobiont expansion and colitis in $1110^{-/}$mice. Nature 2012, 487, $104-108$. [CrossRef] [PubMed]

93. Hildebrandt, M.A.; Hoffmann, C.; Sherrill-Mix, S.A.; Keilbaugh, S.A.; Hamady, M.; Chen, Y.Y.; Knight, R.; Ahima, R.S.; Bushman, F.; $\mathrm{Wu}, \mathrm{G}$.D. High-fat diet determines the composition of the murine gut microbiome independently of obesity. Gastroenterology 2009, 137, 1716-1724. [CrossRef] [PubMed]

94. Neyrinck, A.M.; Possemiers, S.; Druart, C.; Van de Wiele, T.; De Backer, F.; Cani, P.D.; Larondelle, Y.; Delzenne, N.M. Prebiotic effects of wheat arabinoxylan related to the increase in bifidobacteria, Roseburia and Bacteroides/Prevotella in diet-induced obese mice. PLoS ONE 2011, 6, e20944. [CrossRef]

95. Reddy, B.S. Diet and excretion of bile acids. Cancer Res. 1981, 41, 3766-3768. [PubMed]

96. Duca, F.A.; Sakar, Y.; Covasa, M. The modulatory role of high fat feeding on gastrointestinal signals in obesity. J. Nutr. Biochem. 2013, 24, 1663-1677. [CrossRef]

97. Kim, K.A.; Gu, W.; Lee, I.A.; Joh, E.H.; Kim, D.H. High fat diet-induced gut microbiota exacerbates inflammation and obesity in mice via the TLR4 signaling pathway. PLoS ONE 2012, 7, e47713. [CrossRef]

98. Litak, J.; Grochowski, C.; Litak, J.; Osuchowska, I.; Gosik, K.; Radzikowska, E.; Kamieniak, P.; Rolinski, J. TLR-4 Signaling vs. Immune Checkpoints, miRNAs Molecules, Cancer Stem Cells, and Wingless-Signaling Interplay in Glioblastoma MultiformeFuture Perspectives. Int J. Mol. Sci. 2020, 21, 3114. [CrossRef]

99. Brown, K.; DeCoffe, D.; Molcan, E.; Gibson, D.L. Diet-induced dysbiosis of the intestinal microbiota and the effects on immunity and disease. Nutrients 2012, 4, 1095-1119. [CrossRef]

100. Hold, G.L. Western lifestyle: A 'master' manipulator of the intestinal microbiota? Gut 2014, 63, 5-6. [CrossRef] [PubMed]

101. Corcoran, S.E.; O'Neil, L.A. HIF1alpha and metabolic reprogramming in inflammation. J. Clin. Investig. 2016, $126,3699-3707$. [CrossRef] [PubMed]

102. Hand, T.W.; Vujkovic-Cvijin, I.; Ridaura, V.K.; Belkaid, Y. Linking the Microbiota, Chronic Disease, and the Immune System. Trends Endocr. Metab. 2016, 27, 831-843. [CrossRef] [PubMed]

103. Derovs, A.; Laivacuma, S.; Krumina, A. Targeting Microbiota: What Do We Know about It at Present? Medecina (Kaunas) 2019, 55, 459. [CrossRef] [PubMed]

104. Katsura, Y.; Asai, S. Evolutionary Medicine of Retroviruses in the Human Genome. Am. J. Med. Sci. 2019, 358, 384-388. [CrossRef]

105. Morais, L.H.; Schreiber, H.L.T.; Mazmanian, S.K. The gut microbiota-brain axis in behaviour and brain disorders. Nat. Rev. Microbiol. 2020, 19, 241-255. [CrossRef]

106. Abdalla, M.M. Central and peripheral control of food intake. Endocr. Regul. 2017, 51, 52-70. [CrossRef]

107. Karl, J.P.; Hatch, A.M.; Arcidiacono, S.M.; Pearce, S.C.; Pantoja-Feliciano, I.G.; Doherty, L.A.; Soares, J.W. Effects of Psychological, Environmental and Physical Stressors on the Gut Microbiota. Front. Microbiol. 2018, 9, 2013. [CrossRef]

108. Matenchuk, B.A.; Mandhane, P.J.; Kozyrskyj, A.L. Sleep, circadian rhythm, and gut microbiota. Sleep Med. Rev. 2020, 53, 101340. [CrossRef]

109. Andrews, P.; Johnson, R.J. Evolutionary basis for the human diet: Consequences for human health. J. Intern. Med. 2020, 287, 226-237. [CrossRef]

110. Monteiro, C.A.; Cannon, G.; Levy, R.B.; Moubarac, J.C.; Louzada, M.L.; Rauber, F.; Khandpur, N.; Cediel, G.; Neri, D.; MartinezSteele, E.; et al. Ultra-processed foods: What they are and how to identify them. Public Health. Nutr. 2019, 22, 936-941. [CrossRef]

111. Kim, K.O.; Gluck, M. Fecal Microbiota Transplantation: An Update on Clinical Practice. Clin. Endosc. 2019, 52, 137. [CrossRef] [PubMed]

112. Lee, P.; Yacyshyn, B.R.; Yacyshyn, M.B. Gut microbiota and obesity: An opportunity to alter obesity through faecal microbiota transplant (FMT). Diabetes Obes. Metab. 2019, 21, 479-490. [CrossRef] [PubMed]

113. Kootte, R.S.; Levin, E.; Salojarvi, J.; Smits, L.P.; Hartstra, A.V.; Udayappan, S.D.; Hermes, G.; Bouter, K.E.; Koopen, A.M.; Holst, J.J.; et al. Improvement of Insulin Sensitivity after Lean Donor Feces in Metabolic Syndrome Is Driven by Baseline Intestinal Microbiota Composition. Cell Metab. 2017, 26, 611-619. [CrossRef] [PubMed] 